\title{
An unidentified factor in liver required for reproduction in rats
}

\author{
BY B. P. WIESNER AND JOHN YUDKIN \\ Department of Nutrition, Queen Elizabeth College, University of London \\ (Received 27 Fune 1957-Revised 30 October 1957)
}

It has been known for some time that reproduction in rats is impaired when they are fed on purified diets, and may to some extent be restored by supplements of natural foods such as liver (see, for example, Mapson, r932; Folley, Henry \& Kon, 1947). This earlier work was carried out before the recognition of vitamin $B_{12}$ as an essential nutrient.

We too have reported on the effect on reproduction in rats of purified diets containing all the known nutritional factors except vitamin $\mathrm{B}_{12}$ and folic acid (Wiesner \& Yudkin, I95 I). On this diet, female rats of our albino strain K.C. I took longer to conceive, gained less weight during pregnancy and produced smaller litters than female rats reared on a non-purified stock diet. The most outstanding effect was the complete extinction of true fertility, since all the young born died in an emaciated condition within a few days of birth. The supplementation of the purified diet with fresh or dried liver improved reproductive performance and resulted in the survival of more than one-third of the litters. The non-viability of the pups, which is the central characteristic of the deficiency induced by the purified diets, was not repaired to the same extent by vitamin $B_{12}$ as by liver (Wiesner \& Yudkin, 1952). We therefore concluded tentatively that liver contains a factor necessary for normal reproduction, which we have called Factor R. It must not be presumed, of course, that liver is unique in aiding the successful rearing of young by rats given our purified diet. Comprehensive tests for its presence in other foodstuffs have not yet been carried out.

The first part of this communication describes an experiment designed to test that conclusion more decisively by supplementing the purified diets with folic acid and larger doses of vitamin $\mathrm{B}_{12}$. We were not concerned with the relative fertility of animals on purified and on stock diets, but with a comparison between the preventive effects of liver or of a liver preparation, and of vitamin $B_{12}$. The second part is concerned with the effect of the purified diets on reproduction in a different strain of rats.

\section{EXPERIMENTAL}

Experiment I

Six groups of rats of our albino strain K.C. I, each consisting of twenty female weanling animals, aged 23 days, were constructed by litter-mate distribution. The rats were put in individual cages and given free access to water and to purified diet no. 326 (Table I). This diet was similar to that used in previous experiments. The differences were, 
Table I. Composition of diets

$\quad$ Component
Sucrose
Low-vitamin casein
Salt mixture
Arachis oil
Choline chloride
L-Cystine
Dry vitamin mixture

Diet 326

Amount Composition of dry vitamin mixture $(\mathrm{g} / \mathrm{kg})$

600 Inositol $2 \cdot 2$

$200 \quad$ Nicotinic acid $\quad 1 \cdot 0$

5o $\mathrm{Ca}-\mathrm{D}$-pantothenate $\quad \mathrm{r} \cdot \mathrm{O}$

I50 $\quad$-Aminobenzoic acid 0.75

I Thiamine 0.05

2 Riboflavin 0.3

0.539 Pyridoxine 0.08

Biotin 0.002

Folic acid 0.01

In addition, $100 \mathrm{mg}$ cod-liver oil containing $400 \mu \mathrm{g}$ vitamin $\mathrm{K}$ were given twice weekly (Mondays and Fridays), and $2 \mathrm{mg} \alpha$-tocopheryl acetate in arachis oil once weekly (Wednesdays). This procedure ensured that the vitamin $\mathrm{E}$ was not destroyed by the cod-liver oil.

Diet 327

As basal diet 326 with the addition of $100 \mu \mathrm{g}$ vitamin $B_{12} / \mathrm{kg}$ diet

Diet 328

As basal diet 326 with the addition of $200 \mu \mathrm{g}$ vitamin $B_{12} / \mathrm{kg}$ diet

firstly, that folic acid was included and, secondly, that it and the other vitamins of the B group were not given separately but were incorporated in the diet. The diets of the six groups were as follows:

Group I (control) Diet 326 alone. This group thus had neither vitamin $B_{12}$ nor liver

Group 2 (fresh liver) Diet 326 with $\mathrm{I} g$ fresh beef liver daily

Group 3 (dried liver) Diet 326 with $0.26 \mathrm{~g}$ daily of dried liver, from the same batch as used in our earlier experiments (see Wiesner \& Yudkin, I95 I)

Group 4 (vitamin $\mathrm{B}_{12}$ ) Diet 327 from weaning to pairing. This diet was similar to the basal diet 326 , except for the incorporation of $100 \mu \mathrm{g}$ vitamin $\mathrm{B}_{12}$ in each $\mathrm{kg}$ of diet. After pairing, diet 328 was given, in which the vitamin $B_{12}$ was increased to $200 \mu \mathrm{g} / \mathrm{kg}$

Group 5 (dried liver Diets 327 and 328 , as for group 4 , with the addition of $0.26 \mathrm{~g}$ and vitamin $\left.\mathrm{B}_{12}\right)$

Group 6 (delayed dried liver daily

supplementation)

Diet 326 with no supplementation until pairing, and thereafter $\mathrm{I} g$ fresh liver daily

The liver supplements for groups $2,3,5$ and 6 were given daily separately from the diet, and were readily eaten by all the animals.

At the age of 16 weeks, the female animals were paired with the litter brothers reared on the stock diet (see Wiesner \& Yudkin, I95 I). The does were placed with the bucks during the night and a strict rotation of pairing was observed so as to eliminate any effects due to variation in male fertility. The does were examined daily for vaginal plug and in its absence vaginal smears were examined for the presence of spermatozoa. After the placental sign appeared, the does were no longer paired and were given wood wool as nesting material. Litters were kept under careful observation and if they 
survived were weaned at 23 days. They were kept for another 5 days to ascertain postlactational viability. The usual standards of animal care were observed, including the use of raised grids in the cages, controlled temperature and the giving of fresh water daily.

\section{Experiment 2}

Dryden, Hartman \& Cary (1952) were able to maintain fertility in their rats by the incorporation of vitamin $\mathrm{B}_{12}$ in the purified diets. These workers also showed that the deficient animals showed varying degrees of impairment of fertility. Some were unaffected, and their resistance to deficiency was transmitted through successive generations. Because of these two facts, we were interested to see whether in another strain the effect would be less lethal, and if so to use it in cross breeding with K.C. I to learn something of the genetic background of the effect. For this purpose we used a highly fertile strain of hooded rats of the Lister strain, which were not bred, as was K.C. I, by brother-sister mating.

Two groups of fifteen weanling does were constructed by litter-mate distribution and placed on purified diet 326 . Group I received only the purified diet, and group 2 received the same diet, with an addition of $0.26 \mathrm{~g}$ of the batch of dried liver used in the previous experiment. The same procedure was followed as described earlier.

\section{RESULTS}

\section{Experiment $\mathrm{I}$}

Growth before pregnancy. All the groups grew well, though not optimally (Table 2 ). There was no difference in growth rate between the supplemented groups $2-5$. The unsupplemented groups $\mathrm{r}$ and 6 grew somewhat more slowly, though not significantly so $(P<0.5)$. It was noted, however, that the animals receiving liver, in groups 2,3 and 5 , had better muscular tone and better coats than the non-liver groups.

Interval from pairing to parturition. This interval was greatest in the non-supplemented group I and shortest in group 2 which received fresh liver throughout the

\section{Table 2. Exp. I. Mean weights $(g)$ of experimental female rats from weaning to pairing}

\begin{tabular}{|c|c|c|c|c|c|c|}
\hline Time & $\begin{array}{l}\text { Group I } \\
\text { (control) }\end{array}$ & $\begin{array}{c}\text { Group 2 } \\
\text { (fresh liver) }\end{array}$ & $\begin{array}{c}\text { Group } 3 \\
\text { (dried liver) }\end{array}$ & $\underset{\text { (vitamin } B_{12} \text { ) }}{\text { Group }}$ & $\begin{array}{c}\text { Group 5 } \\
\text { (dried liver } \\
\text { and } \\
\text { vitamin } B_{12} \text { ) }\end{array}$ & $\begin{array}{c}\text { Group } 6 \\
\text { (delayed } \\
\text { supple- } \\
\text { mentation } \\
\text { with fresh } \\
\text { liver) }\end{array}$ \\
\hline $\begin{array}{l}\text { At weaning, } \\
\text { age } 23 \text { days }\end{array}$ & $32 \cdot 0$ & $3 \mathrm{I} \cdot 8$ & $3 I \cdot 8$ & $32 \cdot 0$ & $32 \cdot 3$ & $32 \cdot 2$ \\
\hline $\begin{array}{l}\text { After } 4 \text { weeks, } \\
\text { age } 5 \text { I days }\end{array}$ & $106 \cdot 3$ & I I $2 \cdot 9$ & 113.7 & I 12.2 & $114: 3$ & $107 \cdot 2$ \\
\hline $\begin{array}{l}\text { After } 8 \text { weeks, } \\
\text { age } 79 \text { days }\end{array}$ & $I 6 I \cdot 6$ & 164.7 & 163.7 & $163^{*} 4$ & 162.6 & $\mathrm{r}_{57.9}$ \\
\hline $\begin{array}{l}\text { After } 12 \text { weeks, } \\
\text { age } 107 \text { days }\end{array}$ & $185^{\cdot 1}$ & 189.8 & I $89 \cdot 3$ & I $89 \cdot 9$ & 187.4 & I 83.8 \\
\hline $\begin{array}{l}\text { Increase in } \\
12 \text { weeks }\end{array}$ & I 53.1 & 158.0 & I 57.5 & r 57.9 & $155^{\prime} \mathrm{I}$ & $\mathrm{I}_{5} \mathrm{I} \cdot 6$ \\
\hline
\end{tabular}


experiment. None of the differences, however, were significant and they were caused chiefly by a few long delays in the groups with longer mean intervals. The delays in conception were not due to failure to copulate, but to the occurrence of infertile matings. Thus, sixteen infertile matings were recorded in group $\mathbf{I}$, which were not followed by phases suggestive of pseudo-pregnancy.

Maternal weight increment during gestation. The increase in weight during gestation (from copulation to eve of parturition) was higher in the groups receiving liver, groups $2,3,5$ and 6 , than in those receiving no liver. But the only significant difference was between the control group $I$ and the group receiving liver and vitamin $B_{12}$, group 5. Maternal somatic increase was lowest in the control group; the differences were significant between this group and group 3 and group 5, that is the groups receiving dried liver.

Maternal behaviour. We recorded the efficiency of nest building on an arbitrary scale from o for absence of nest building to 4 for the building and maintenance of a good nest. In the control group $I$, only one animal built a fairly good nest, and in the vitamin $\mathrm{B}_{12}$ group 4 , none did so. In the fresh-liver group 2 , seven animals built and maintained good nests; in the dried-liver groups 3 and 5 , without and with vitamin $B_{12}$, three and four animals did so. In the delayed-supplementation group 6, three animals did so. Similar differences between the groups were noted in other aspects of behaviour; thus readiness to retrieve their young was absent in most animals in group I, and well developed in groups 2 and 5.

Litter size. Since some of the pups were stillborn, and others died soon after birth, and since some of these and possibly other pups were eaten by the mothers, it was not possible to determine exactly the size of the litters. The figures in Table 3 are therefore the sizes of litters at first count, at the first opportunity after birth. The control group $\mathrm{I}$ had a somewhat lower litter size than the other groups, but none of the differences were significant.

Birth weight of young. The litters were weighed, as well as counted, as soon as possible after birth. The control group I had pups of lowest average weight. Though the difference between this and any single other group was not significant, there was a significant difference between the control group, and the combined other groups $(P=0.03)$.

Viability. Of the ${ }_{1} 6$ pups born in the control group, 148 died in the first 3 days and the remaining 8 in the next 4 days. In the groups receiving fresh or dried liver, whether given from weaning or only after pairing, at least some pups survived in between one-half and one-quarter of the litters. In both groups 2 and 5, one litter survived in its entirety; in all the other litters in these and other groups at least one pup died, usually in the first 4 days. The mortality of the pups is given in Table 4 .

In the liver-supplemented groups, $20-38 \%$ of the pups survived. In the groups supplemented only with vitamin $B_{12}$ nineteen out of twenty litters died in their entirety; seven out of nine pups survived in the remaining litter.

Early death of the pups did not appear to be due to failure or inadequacy of lactation. Soon after birth, the young were found to have obtained some milk, although the apparent area of the milk sign varied. Many of the pups appeared to stop suckling 


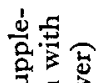

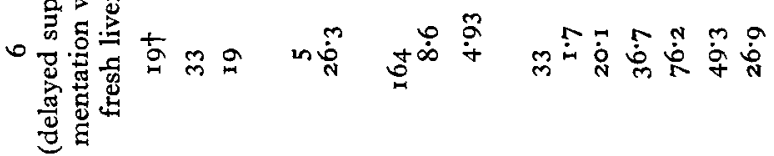

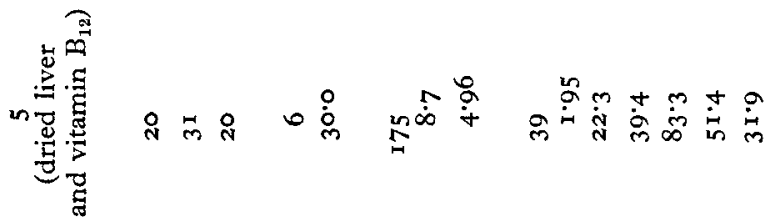

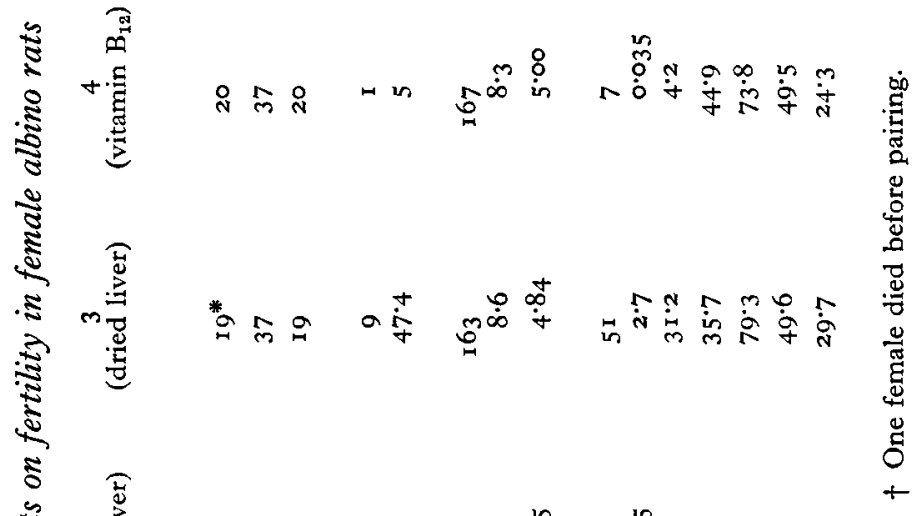

莺

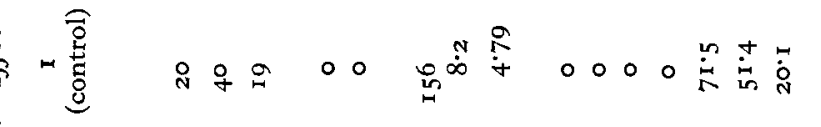

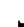

ड्ड़่ :

$\dot{n}$

$\frac{0}{\frac{0}{0}}$

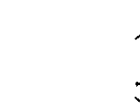

绻

蓠

:

!

!

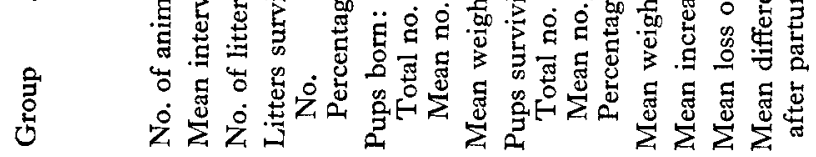


about $24 \mathrm{~h}$ before death. Autopsy showed depleted intestines and very little milk in the stomach.

Survival after weaning. Surviving pups were weaned on to the maternal diet at 23 days, irrespective of their condition. They were maintained for at least 5 more days, and none of them died during this short time.

\section{Table 4. Exp. 1. Percentage of pups born which were surviving on selected days after birth}

$\begin{array}{ccccccc}\text { Day } & \begin{array}{c}\text { Group I } \\ \text { (control) }\end{array} & \begin{array}{c}\text { Group 2 } \\ \text { (fresh liver) }\end{array} & \begin{array}{c}\text { Group 3 } \\ \text { (dried liver) }\end{array} & \begin{array}{c}\text { Group 4 } \\ \text { (vitamin B }\end{array} & \begin{array}{c}\text { Group 5 } \\ \text { (dried liver } \\ \text { and }\end{array} & \begin{array}{c}\text { Group } \\ \text { (delayed } \\ \text { supplemen- } \\ \text { tation with } \\ \text { vitamin B }\end{array} \\ \text { fresh liver) }\end{array}$

Growth of pups during lactation. The mean increase in weight of pups during lactation in the various groups was not significantly different. As in the vitamin $B_{12}$ group 4 only one litter survived, the significance of its apparently greater weight at weaning cannot be assessed. The growth during lactation was about the same as that of contemporary litters reared by females on the stock diet. There was also no difference in growth increment in the various groups in the short time after weaning.

Correction of deficiency. The animals in group 6, which received liver only from pairing onwards, showed nearly as good fertility as the groups receiving liver from weaning. In order to gain further information regarding this correction of Factor $\mathrm{R}$ deficiency, animals from groups $\mathrm{I}$ and 4 , that is the control animals and those given vitamin $B_{12}$, were again paired 4 weeks after the end of the experiment and given liver supplement. Not only were no litters reared from either group, but in fact none of the animals conceived although mating took place readily.

\section{Experiment 2}

The results are given in Table 5 . The animals in both groups grew reasonably well. There was a significantly greater increase in weight $(P=0.0 \mathrm{I})$ in the first 4 weeks in the animals receiving liver, but it tended to diminish later.

The mean interval from pairing to parturition was within the range usually observed in this strain when fed on the stock diet. However, three animals in the control group produced no litter. One failed to copulate, and in the other two the appearance of the placental sign and the increase in maternal weight suggested parturition followed immediately by cannibalism.

The litter size was significantly greater in the supplemented group. It was unlikely to be due entirely to less cannibalism, since the mean increase of weight during gestation and the mean loss of weight at parturition were also greater in this group.

The chief difference here, as in experiments with strain K.C. I, was in the viability 
of the young. In the supplemented group, seven litters survived to weaning, with thirty-eight pups. In the control group, only one litter survived to weaning, with four pups. These did not flourish and just before weaning they were found to be subject to audiogenic seizures. They also grew badly after weaning, and soon had to be discarded.

Table 5. Exp. 2. Effect of supplements on fertility in hooded rats

\begin{tabular}{|c|c|c|}
\hline Group ... & $\begin{array}{c}\mathbf{I} \\
\text { (control) }\end{array}$ & $\stackrel{2}{2}$ (dried liver) \\
\hline No. of animals & I 5 & 15 \\
\hline Mean weight 4 weeks after weaning (g) & $124 \cdot 8$ & $133 \cdot \tau$ \\
\hline Mean interval between pairing and birth of litter (days) & 30 & 34 \\
\hline No. of litters born & 12 & I 5 \\
\hline $\begin{aligned} & \text { Litters surviving to weaning: } \text { no. } \\
& \text { percentage of total }\end{aligned}$ & $\begin{array}{l}\text { I } \\
8 \cdot 33\end{array}$ & $\begin{array}{c}7 \\
46 \cdot 67\end{array}$ \\
\hline $\begin{array}{l}\text { Pups born: total no. } \\
\text { mean no./litter }\end{array}$ & $\begin{array}{l}87 \\
7 \cdot 25\end{array}$ & $\begin{array}{l}\text { I } 57 \\
10.47\end{array}$ \\
\hline Mean weight of newborn pups (g) & $4 \cdot 55$ & $4 \cdot 82$ \\
\hline $\begin{array}{l}\text { Pups surviving to weaning: total no. } \\
\qquad \text { mean no./litter }\end{array}$ & $\begin{array}{l}4 \\
0.33\end{array}$ & $\begin{array}{l}38 \\
2 \cdot 53\end{array}$ \\
\hline Mean increase in weight during gestation $(\mathrm{g})$ & $73 \cdot 3$ & $92 \cdot 9$ \\
\hline Mean loss of weight during parturition (g) & $52 \cdot 1$ & $64 \cdot 0$ \\
\hline Mean difference between weight at copulation and & $2 I \cdot 2$ & $28 \cdot 9$ \\
\hline
\end{tabular}

\section{DISCUSSION}

The lethal effect upon the offspring of purified diets lacking liver, which was reported in our previous communications (Wiesner \& Yudkin, 1951, 1952), was again established in the present experiments. We have now reared fifty-five does of strain K.C. I on such diets, and without vitamin $\mathrm{B}_{12}$ no viable offspring has been obtained from any of them.

Nature of deficiency. From these and previous experiments, it is evident that the lethal effect of the purified maternal diet does not derive from an inhibition of lactation. We have earlier reported that some of the young from does on stock diets can be successfully brought to weaning by does fed on the purified diet. We have also shown, conversely, that young from deficient mothers can survive when fostered by stock mothers. We concluded that the deficiency affects both the mothers and the young. In the mothers, the deficiency showed itself by faulty nest building and impaired retrieving response; it is likely that these are but two more obvious of the functions needed for the successful rearing of young. In the young, the deficiency showed itself in their appearance, in their earlier failure to suckle, and in their decreased spontaneous activity.

The present results confirm that the effect of liver supplementation in overcoming, to a great extent, the lethal effect of the purified diet is not due to its content of vitamin $\mathrm{B}_{12}$.

In our previous experiment with vitamin $B_{12}$ (Wiesner \& Yudkin, I952), I $\mu \mathrm{g}$ of the vitamin weekly gave a slight degree of protection against the lethal effect of a purified diet. Although this amount of vitamin $B_{12}$ is probably adequate, we have given more 
in the present experiment. The mothers ate on an average $10 \mathrm{~g}$ or more of the diet daily, so that they were receiving at least $\mathrm{I} \mu \mathrm{g}$ vitamin $\mathrm{B}_{12}$ daily before pairing, and twice this amount during pregnancy. They obtained less vitamin $B_{12}$ from fresh liver, which contains $0.3^{-1} \circ \mu \mathrm{g} / \mathrm{g}$ and probably still less from the dried liver, which contained $0.3 \mu \mathrm{g}$ in the daily dose of $0.26 \mathrm{~g}$. Yet the fresh and the dried liver afforded much more protection to the young than vitamin $B_{12}$. Thus, the effect of fresh or dried liver is not duplicated by vitamin $B_{12}$ in quite adequate amounts, nor is it related to the amount of vitamin $B_{12}$ in the liver. Nor does vitamin $B_{12}$ enhance the protective effect of the active preparation of dried liver. Hence the present results support the view that reproductive Factor $\mathrm{R}$ is not identical with any of the known dietary factors.

It appears, however, that in some individuals or in some strains, vitamin $B_{12}$ may either replace Factor $\mathrm{R}$ or promote its intestinal synthesis. In our experiments, supplemental vitamin $B_{12}$ occasionally gave viable progeny. Other workers have found that supplemental vitamin $\mathrm{B}_{12}$ entirely corrects the impairment of fertility occurring with purified diets (e.g. Dryden et al. 1952).

We have previously reported that liver contains a growth factor which is not identical with any identified nutrient (Yudkin, 1952). The growth factor is also probably different from Factor $\mathrm{R}$, since cod-liver oil is active in improving reproduction but does not promote growth. Factor $\mathrm{R}$ would thus appear to be a unique nutrient, since it is essential during only that short period of the life cycle which is concerned in conferring viability upon the newborn young.

Though in this experiment, as in earlier ones, fresh or dried liver afforded protection against the central effect of purified diets in producing non-viable young, there was here, unlike in our early experiments, little effect on litter size, weight of pups and maternal weight increment during pregnancy. It is possible that these improvements in reproductive behaviour were due to the incorporation of folic acid in the diets. This point requires further investigation. Nevertheless, it suggests that the various detrimental effects of purified diet upon fertility are caused by a deficiency of a variety of nutritional factors. We imply by the term Factor $\mathrm{R}$ only the substance or substances without which the young are non-viable.

We have shown that delayed supplementation, in which liver was given only from pairing, results in a significant increase in rate of survival, though to a lesser degree than the feeding of liver from weaning. Thus, the deficiency caused by the absence of Factor $\mathrm{R}$ up to the time of pairing is at least partially reversible. However, the reversibility of the deficiency is severely limited since, as we have seen, no further conception took place in the animals not given liver in the initial part of the experiment and then given liver after pairing a second time.

Apart from its immediate significance, the reversibility of the deficiency during pregnancy suggests that it may be possible to demonstrate the Factor $R$ activity of a preparation of liver within about 6 weeks, that is from the pairing of the mother to the weaning of the litter. In the standard experiments we have used hitherto, feeding with the supplement is begun at weaning of the does, so that $I 7$ weeks is necessary. This more rapid technique will, it is hoped, facilitate further study of Factor R.

The lethal effect on the young of purified maternal diets was not confined to our 
highly inbred strain K.C. I, but also appeared in a strain not subject to brother-sister mating, which suggests that the effect of highly purified diets in causing severe infertility is not confined to exceptional strains of rats.

\section{SUMMARY}

I. Six groups, each of twenty female albino rats, were fed from weaning on a purified diet containing all the known nutritional factors except vitamin $\mathrm{B}_{12}$. One group acted as control, and the other five groups were given supplements. The animals were paired at $\mathrm{I} 6$ weeks of age with bucks fed on a stock diet.

2. The supplements were given to four of the experimental groups from weaning, and consisted of fresh liver, dried liver, vitamin $B_{12}$, and dried liver with vitamin $B_{12}$. The fifth experimental group was given fresh liver from pairing.

3. Of the 153 pups born to the control animals, all died within 8 days. Of the 167 pups born to animals receiving vitamin $B_{12}$, seven survived to weaning. Of the $164-182$ pups born to the animals in the other groups, receiving fresh or dried liver, 33-69 survived to weaning. The mothers in the groups not receiving liver showed poor maternal behaviour.

4. There was a tendency for the animals not receiving liver to gain less weight during pregnancy, and to have smaller litters, with lighter pups. In this experiment, unlike in those previously reported by us, these differences did not reach the usual criteria of significance.

5. We conclude that this strain of rats requires an unidentified nutritional substance, or substances (Factor R), present in liver, for the production of viable young. Factor $\mathrm{R}$ can exert its effect, at least to some extent, when given only during pregnancy.

6. A strain of hooded rats showed the same need for Factor R. From fifteen does fed on the purified diet, only four poorly developed pups survived to weaning. From fifteen does fed on the same diet with liver, thirty-eight pups survived to weaning. In this experiment, the unsupplemented animals showed a significantly smaller gain in weight during pregnancy, and produced significantly smaller litters.

We are grateful to Mrs E. Blacker for her meticulous care of the animals, and to Genatosan Ltd for a generous grant towards the expenses of the Department.

\section{REFERENCES}

Dryden, L. P., Hartman, A. M. \& Cary, C. A. (1952). F. Nutr. 46, 281 .

Folley, S. J., Henry, K. M. \& Kon, S. K. (1947). Brit. F. Nutr. I, 39.

Mapson, L. W. (1932). Biochem. F. 26, 970.

Wiesner, B. P. \& Yudkin, J. (195I). Nature, Lond., 167, 979.

Wiesner, B. P. \& Yudkin, J. (1952). Proc. Soc. Stud. Fertil. 3, 46.

Yudkin, J. (1952). Brit. med. F. i, I 388. 